\title{
Discussion on the Reform of College Chinese Teaching Mode in the New Media Era
}

\author{
Zeng Hua \\ Changsha Vocational and Technical College, Changsha, Hunan Province, 410217
}

Keywords: new media era; College Chinese; teaching mode reform

\begin{abstract}
The teaching of College Chinese is an important way to cultivate students' humanistic quality and ideological and moral cultivation. It is not only conducive to the comprehensive improvement of students' general quality, but also to the inheritance and development of excellent traditional culture. In the new media era, College Chinese teaching should conform to the development trend of the times and explore new ways of reform and innovation. The first part of this paper expounds the important role of College Chinese and its profound influence. The second part analyzes the problems existing in the process of College Chinese teaching in the new media era, and explores the reasons. Finally, in order to improve the teaching level of College English in China and adapt to the development trend of the new media era, specific innovative measures are put forward for the existing problems.
\end{abstract}

\section{The Study of the Important Role of the College Chinese}

Chinese is a broad and profound subject, whether it's work study or daily life. In developing the course of College Chinese, we can cultivate students' individuality, improve their humanistic quality and promote their all-round development. First of all, in the process of Developing College Chinese teaching activities, by learning excellent works, students can learn a variety of culture. In the teaching content of College Chinese, excellent literary works can bring spiritual baptism to students and enrich their emotional world. In the process of learning Chinese, students can understand the spiritual connotations of these literary works and enable students to turn learning into a very enjoyable thing. Literary and artistic works enable students to see the essence through their works, to understand the true, the good and the beautiful, and to understand the true meaning of life. Under the guidance of literature and art, college students can see life and feel life more aesthetical. Secondly, College English can cultivate students' divergent thinking and creativity, and improve their EQ when they are used. On the one hand, in the process of learning Chinese, college students can cultivate their imagination, enrich people's imagination and enhance their creativity. Creativity is an important driving force for people's progress. College Chinese can effectively cultivate students' initiative creativity. On the other hand, learning college Chinese can improve students' EQ. Many times, the literary works can create a very distinctive character and personality, and often these characters will have strong inspiring ability to cultivate students' positive and optimistic attitude to life, and the spirit of never to be defeated in the face of difficulties and setbacks [1].

Thirdly, learning Chinese can enhance students' ability of language expression and enhance their interpersonal skills. Communication and communication between people is an important ability in life. People live in this world and need to express their thoughts through language at anytime and anywhere. Both in daily life and in work learning, language expression and language abilities are very important. The university language can enhance the students' language expression ability, promote communication and communication with others, build a harmonious interpersonal relationship, and make the students' life more enjoyable. Finally, learning Chinese can enhance students' lifelong learning ability and provide spiritual impetus for students in the future. In the mode of examination oriented education, many students think when they think, it is difficult to jump out of the fixed mode to look at the problem. After the thinking pattern, it is not so easy to change. Therefore, it is not easy for students to form innovative thinking, which is not conducive to accepting new things. In the course of learning Chinese, the students' learning and thinking ability 
can be cultivated, the connotation of thought is enriched, and the way of thinking is active, which helps to promote the students to learn other professional knowledge more effectively [2].

\section{The Problems Existing in the Teaching Mode of College Chinese in the New Media Era}

\subsection{The teachers of College Chinese are relatively weak}

On the one hand, the teaching enthusiasm of College Chinese teachers needs to be improved. Because the status of College Chinese course is not high in many universities, many college Chinese teachers are not very high. Therefore, it is difficult to arouse the teachers' enthusiasm for teaching. On the other hand, the teaching level of university teachers is relatively low, lack of awareness of classroom innovation, and still adopt a single mode of teaching, which leads to more boring teaching activities and traditional teaching methods. In the long run, it will hurt students' enthusiasm for learning and is not conducive to cultivating students' interest in learning.

\subsection{Students lack interest in learning Chinese}

From the present point of view, few college students learn Chinese knowledge, appreciate literary works and feel the true meaning of life in literary works. From this, it can be seen that students lack the enthusiasm to learn Chinese. On the one hand, many people think that college Chinese is a basic course, and there is no other course that is so practical, but it ignores the great role that Chinese can play. Some college students think that language courses have no practical value, and seldom spend time and energy to study the subject, only to deal with the final examination and the study before the exam. One reason is that the teaching mode of the College Chinese is relatively traditional, and the teaching method lacks innovation measures, which leads to the lack of enthusiasm for the students.

\subsection{University classroom teaching method is single, teaching means are more traditional [3]}

First of all, the teaching mode of College Chinese has always been a large class teaching mode. Classroom teaching activities are difficult to organize effectively. Therefore, teachers can only take a relatively single lecture in the course of teaching, which leads to the dull atmosphere in the classroom. The interaction and communication between teachers and students is less, the effect of teaching has not reached the expected effect, and the quality of teaching is not improved. Secondly, in the course of College Chinese classroom teaching, the students lack the subjectivity, the teachers do not give full play to the guiding role, the students' enthusiasm is difficult to be mobilized, leading to the students' participation in the class is not high. Finally, the classroom teaching tools of the university language are relatively simple, and many media modern teaching techniques are not used. To a certain extent, it is not conducive to the students to cultivate their imagination and thinking ability, which hinders the students to cultivate their active creativity. Therefore, the university classroom teaching method is single, no effective use of modern technology, teaching means more traditional, lack of innovative consciousness, affecting the students' learning enthusiasm.

\subsection{There is a shortage of College Chinese textbooks, and there is no teaching material suitable for students [4]}

As far as the current situation is concerned, there are many similarities between the teaching materials of Chinese College Chinese and the teaching materials of Chinese and senior high and high school. The teaching content is old and does not conform to the development trend of the times. Therefore, it can not attract the attention of college students and can not improve the interest of learning. At the same time, the College Chinese textbooks lack a standard general standard, there is no unified syllabus, in many cases, the teachers themselves write the language textbooks used by the school. There are great differences in the methods of writing teaching materials in each school, and there are different points and emphasis, and there is a lack of a standard standard of writing. There are obvious deficiencies in the textbooks they have written, which is not conducive to the improvement of the quality of College Chinese teaching, and it is also very difficult to achieve 
teaching objectives.

\section{The Teaching Methods of College Chinese in the New Media Era}

Build a high level of teaching staff and improve the teaching level of teachers. With the development of the times, the university language teachers have also put forward new requirements. Therefore, it is very important to strengthen the construction of the teaching staff and improve the level of the University Language Teachers in an all-round way. On the one hand, teachers should master the rich cultural knowledge and have a certain knowledge reserve. In the course of teaching Chinese, they can impart their knowledge to the students, expand the knowledge of the students, enrich the connotation of literature, and improve their learning ability and creativity. On the other hand, College Chinese teachers should have rich teaching experience and high level of teaching skills. They are good at enlightening and guiding students to understand literary knowledge, forming a unique style of teaching and giving full play to the guiding role of teachers. Therefore, building a high level of teachers, improving the teaching level and teaching skills of teachers can not only promote the overall development of the students, but also improve the quality of teaching and promote the inheritance and development of our country's excellent culture

In order to improve students' learning enthusiasm, teachers should innovate the teaching mode and teaching method in the process of College Chinese teaching. First of all, in the classroom teaching content, we must ensure that the content of the teaching is very good and embodies certain literary value. Therefore, the university language classroom should abide by the principle of the teaching content, and make every valuable literary content thorough, so that the students can grasp the literary knowledge more deeply. Secondly, in teaching methods, we should learn to talk about literary classics in the framework of literary history, so that students can learn literature more intuitively. At the same time, we should combine the literary story with the historical stories of the literati and show them to the students, so that the students can understand the literary works more comprehensively and master the literary knowledge. Finally, in the process of teaching, teachers should make full use of teaching aids to enrich classroom activities. With the rapid development of modern information technology, it provides many favorable resources for classroom teaching. In the face of such a multimedia era, teachers should make full use of classroom auxiliary tools to carry out innovative teaching methods. The use of multimedia to effectively combine literature and literature, and also to carry out a series of reading, discussion and appreciation of the literary works, not only to cultivate students' ability to explore actively, but also to promote the effective dissemination of Chinese excellent culture. Therefore, the innovation of College Chinese classroom teaching mode and teaching methods can improve students' interest in learning and enrich the connotation of literary knowledge [5].

With the continuous development of science and technology and modern information technology, modern educational technology has gradually been widely applied to classroom teaching. In this new teaching mode, learning the university language has become a very conscious thing, not only fully mobilize the students' learning enthusiasm, enhance the students' understanding of the language knowledge, but also effectively improve the students' task accomplishment. In the course of specific teaching activities, teachers should not only use the traditional teaching mode, but also combine the multimedia courseware to integrate the two, enrich the classroom teaching activities, improve the teaching mode and improve the quality of teaching. On the other hand, the use of self media teaching tools in Chinese classroom will expand the communication space of College Chinese teaching. From the media platform, as long as there are QQ, micro-blog, WeChat, post bar, forum and so on, in these self media platforms, teachers can use a very wide range of platforms, such as QQ, the WeChat public number. In the process of Teaching College Chinese, teachers can make full use of modern media technology, such as the media, to assist teaching. Teachers can take class as the unit QQ group or WeChat group, uploading the task content and expanding content after class, let the students learn Chinese independently, and carry out effective knowledge discussion in the group to improve the students' enthusiasm and participation. At the same time, teachers can find some interesting literary stories on the WeChat public platform, and some excellent chapters that 
conform to the development of the times, increase the students' learning knowledge, broaden their horizons, and make the students master the language knowledge more deeply. Therefore, the teachers use multimedia to enrich the classroom teaching mode, and use the media to expand the communication space of the university language teaching. It can effectively activate the classroom atmosphere, enrich the learning activities under the course and improve the teaching quality.

On the one hand, in order to improve the level of College Chinese teaching and achieve the goal of language teaching, it is very important for students to choose suitable textbooks for practical needs. From the current teaching development, we can combine the contents of the university language content according to the actual situation, and add some new contents that conform to the development trend of the times. In the process of compiling textbooks, we must ensure that the contents of the textbooks should be full of knowledge and highlight certain value meanings. At the same time, it should be close to the actual life, stimulate the students' learning enthusiasm, improve the students' subjective initiative, and make them the main motive force to promote the students to learn Chinese effectively. On the other hand, after graduating, college students will enter jobs. Language skills and expression skills are necessary skills. Therefore, it needs to be taught in the course of College Chinese teaching, and the students can better master the writing skills and use the language skills through Chinese teaching. At the same time, when choosing the appropriate teaching content, it is necessary to combine the actual situation of the students with the teaching objectives of the university language, so that the teaching content can be aimed at cultivating the students. In the process of learning the Chinese language, the students can understand the culture of our country more comprehensively and establish a systematic literature knowledge network, so as to more effectively master the cultural characteristics of each period of our country, so as to enrich its own cultural connotation. Therefore, to strengthen the reform of the College Chinese teaching materials and carefully set up the teaching content of the university language, it can be more targeted to cultivate the students' comprehensive ability and promote the all-round development of the students [6].

\section{Conclusion}

Literature is the essence of human thought. It can wash people's hearts and sublimate their inner souls. In the process of learning Chinese, we can establish and improve people's personality, enrich people's spiritual world, and promote people's all-round development. College Chinese is an important course which can establish and improve students' ideological character and promote the inheritance and development of excellent traditional culture. Conforming to the new media era to innovate the teaching methods of College Chinese is conducive to promoting the teaching of Chinese with the times, improving the teaching quality and education level of the College Chinese, and improving the teaching effect. Although at the present stage, under the influence of the new media, there are some problems in the course of the development of the university language. However, with the continuous reform and improvement, we conform to the trend of the times and make innovative measures. I believe that the quality of the teaching of the Chinese language course will be improved, so that it will play a real role and promote the students. Face development promotes the development and promotion of our excellent culture.

\section{References}

[1] Xinlai L I, Cao D. Discussion on the Reform of Plant Physiology Teaching under New Era's Background[J]. Farm Products Processing, 2016.

[2] Pan J. Discussion on the Reform in Teaching of the Hygienic Chemistry under the Internet + Era[J]. Guangdong Chemical Industry, 2016.

[3] Mao N, Department B. A Discussion on the Reform of Current College Classroom Teaching Mode based on the Context of New Curriculum Reform[J]. Journal of Hubei Correspondence University, 2016. 
[4] Yuan Z, Ren Y E. Discussion on the Reform of Teaching and Examination Mode of Traditional Chinese Medicine in Medical Universities[J]. Chinese Medicine Modern Distance Education of China, 2018.

[5] Xue M. In the Name of ESP Comments on the Recent Discussion on College English Teaching Reform in China[J].

[6] Guo Y. Discussion on the Reform of Chemical Experiment Teaching in Higher Vocational Colleges[J]. Guangdong Chemical Industry, 2018.

A brief introduction to the author: 1971.2--, female, Han nationality, Changsha, Hunan, lecturer, undergraduate, mainly engaged in Chinese language teaching and higher vocational educational administration research. 